\title{
DA GERÊNCIA PARA A DOCÊNCIA: METÁFORAS DO DISCURSO DE TRANSIÇÃO
}

\author{
Luiz Cláudio Vieira de Oliveira \\ violi@ superig.com.br \\ Universidade Fundação Mineira de Educação e Cultura - Belo Horizonte, MG / Brasil \\ Zélia Miranda Kilimnik \\ zeliamk@gmail.com \\ Universidade Fundação Mineira de Educação e Cultura - Belo Horizonte, MG / Brasil \\ Rafael Parreira de Oliveira \\ r.parreira@hotmail.com \\ Universidade Fundação Mineira de Educação e Cultura - Belo Horizonte, MG / Brasil
}

Recebido em 15/06/2011

Aprovado em 21/09//2012

Disponibilizado em 01/08/2013

Avaliado pelo sistema double blind review

Revista Eletrônica de Administração

Editor: Luís Felipe Nascimento

ISSN 1413-2311 (versão on-line)

Editada pela Escola de Administração da Universidade Federal do Rio Grande do Sul.

Periodicidade: Quadrimestral

Sistema requerido: Adobe Acrobat Reader.

\section{RESUMO}

As mudanças do mundo contemporâneo e das relações de produção, provocadas pela globalização, a evolução da tecnologia e a competição entre organizações para conquista e manutenção de mercados exigiram novos padrões de desempenho e de competência de seus profissionais. A pressão por resultados levou esses profissionais à revisão da própria carreira dentro das organizações e à transição, total ou parcial, para as instituições de ensino superior, favorecedoras de maior liberdade e criatividade. A metodologia empregada foi a Análise do Discurso Francesa, a partir das transcrições de entrevistas realizadas com 22 gerentes que efetuaram a transição para a carreira docente. Investigou-se a relação entre o discurso desses profissionais e o ambiente de mudanças, pressões e exigências de competências que os atingiu. Investigou-se, também, a imagem de si que esses profissionais constroem ao realizarem o processo de transição. Com isso, os resultados apontaram: para a elaboração de uma imagem positiva e idealista de si mesmos e da atividade docente; para uma visão negativa das instituições de ensino (mundo da carochinha) em oposição à imagem positiva e séria do mundo organizacional (mundo real); para a constatação de que o alto nível de pressão por resultados e por competência levou os profissionais, competentes mas tolhidos pelo excesso de exigências, à transição de carreira.

Palavras-chave: Gerência; Docência; Transição de carreira; Metáforas; Análise do Discurso. 
Da gerência para a docência: metáforas do discurso de transição

\title{
FROM MANAGEMENT TO TEACHING: METAPHORS OF TRANSITION DISCOURSE
}

\begin{abstract}
Globalizations, changing technology and competition between organizations have changed the world nowadays. Organizations have undergone changes in their production relations as a response to market demands and, therefore, new performance and competence standards from their professionals have been necessary. The strong pressure for positive results has led organizations professionals to analyze their own career and to migrate to higher education institutions. This study aims to investigate the discourse characteristics presented by twentytwo managers who migrated from organizations to educational institutions. It studies how their discourse relates to the new environment and to its demands of new capacities. The research also investigates the self-image that the informants have developed in their transition process in those new environments. The French Discourse Analysis Theory was used to analyze the interviews that were made. The following conclusions have been pointed out: professionals build up a positive image of themselves and that of teaching activities; they build up a negative opinion of education institutions (an unreal world) as opposed to a positive and reliable image of organizations(the real world). Finally, evidence indicates that high levels of stress for positive results and a permanent demand to improve their capabilities lead competent professionals to career transitions.
\end{abstract}

Keywords: Management; Teaching; Transition; Metaphors; Discourse Analysis.

\section{INTRODUÇÃO}

Este texto, oriundo de pesquisa sobre transição da gerência para a docência, com foco em estratégias de carreira e competências, analisou o discurso de vinte e dois professores de ensino superior, que realizaram a transição da gerência, no mercado corporativo, para a academia, como docentes. Alguns ainda mantêm ligação com as organizações. As entrevistas, feitas em 2009, utilizaram roteiro baseado na contribuição da Prof ${ }^{a}$. Joanne Duberley, da University of Birmingham, pesquisadora do tema transição de carreira (DUBERLEY; COHEN; LEESON, 2006a; DUBERLEY; COHEN; LEESON, 2006b).

Há vários aspectos interligados: o processo de transição, pensado a partir do inventário das âncoras de carreira, proposto por Schein (1993), a situação do indivíduo nas relações de produção nas organizações contemporâneas, o sistema de ensino brasileiro, em geral, e os cursos de Administração, em especial. A transição da gerência para a docência não é só o movimento de um espaço para outro, ou a interrupção de um processo, numa carreira, para reiniciá-lo em outra, segundo Baruch (2003), mas também a questão da competência, que é a

REAd I Porto Alegre - Edição 75 - Nº 2 - maio/agosto 2013 - p. 301-329 
Luiz Claudio Vieira de Oliveira, Zélia Miranda Kilimnik \& Rafael Parreira de Oliveira capacidade de realizar algo e a possibilidade de integrar saberes, em sintonia com mudanças tecnológicas e de informação pelas quais a sociedade está passando.

O conceito de competência ultrapassa o de qualificação (estoque de conhecimentos das pessoas, que podem ser classificados e certificados pelo sistema educacional) e também o de cargo, mais coadunado com as características atuais do mundo do trabalho, pois se refere à “capacidade de a pessoa assumir iniciativas, ir além das atividades prescritas, ser capaz de compreender e dominar novas situações no trabalho, ser responsável e ser reconhecido por isso" (ZARIFIAN, 1994, p. 111).

Competência é um conceito dinâmico, permanentemente atualizado, variando de acordo com o profissional, a organização e o contexto em que se situa (LE BOTERF, 2003). A qualificação do indivíduo é um ponto de partida para a competência, dando-lhe habilidades básicas em sua área (ZARIFIAN, 2001). A competência é algo potencial, acionado quando for necessário. Ser competente demanda do profissional uma atenção e uma tensão permanentes. Isso tem como centro a noção de carreira.

Carreira e profissão se relacionam a trabalho que, segundo Barros (2007, p. 52) “[...] tem um caráter pessoal, constituindo um ato da vontade livre do homem; tem um caráter singular, na medida em que traduz uma expressão do valor e da personalidade de quem o executa". O trabalho manifesta a vontade de cada indivíduo: "O trabalho atua como meio de subsistência, de acesso à propriedade, e cumpre um conjunto de funções sociais" (BARROS, 2007, p. 52). Não se compreende, hoje, alguém que não trabalhe e execute todas essas funções sociais e de subsistência, importantes para a realização e identidade de cada indivíduo (HALL, 2001; ARAÚJO; SACHUK, 2007; COUTINHO; KRAWULSKI; SOARES, 2007).

A partir do Renascimento, a sociedade ocidental adquiriu a fisionomia atual, em relação ao trabalho e à produção, o que envolve os meios de produção, as relações de produção, as forças produtivas e a reprodução das relações de produção. Todos esses conceitos, de origem marxista, podem ser observados no sistema capitalista contemporâneo, assegurando a reprodução das relações de produção, independentemente das mudanças tecnológicas ocorridas a partir da Revolução Industrial, no sec. XIX, e acentuadas desde a segunda metade do sec. XX. A atualização das forças produtivas implica em mais tecnologia, que exige mais atualização das forças produtivas, e assim por diante.

Todo esse processo permanente e interminável se dá dentro da organização onde o trabalhador faz carreira, com pretensão de chegar a posição de destaque. Dada a aceleração do processo descrito, o trabalhador deve desenvolver habilidades e atualizar-se permanentemente, para alcançar sucesso e não ser alijado das relações de produção. Esse REAd I Porto Alegre - Edição 75 - N 2 - maio/agosto 2013 - p. 301-329 
Da gerência para a docência: metáforas do discurso de transição

ajuste constante gera instabilidade e desgaste para o trabalhador, levando-o a reconsiderar sua carreira, seja como um caminho a seguir, seja como forma de chegar a um fim: posição de sucesso ou de destaque dentro do sistema.

Há dois aspectos a considerar: os conceitos de carreira e de atualização, ambos ligados aos conceitos de competência e de competir. Ser competente significa ter capacidade de competir, concorrer, rivalizar-se, entrar em confronto com alguém. Estar numa carreira implica pretender atingir o sucesso: seja atualizando-se permanentemente, seja competindo com outros profissionais com formação e com objetivos profissionais semelhantes.

As organizações fomentam a competição para extrair o máximo de cada profissional, acenando com objetos de desejo cuja conquista demandará maior produtividade e maiores lucros para a organização. Numa sociedade que estimula a concorrência, o sucesso e o individualismo, ser competente é ser vencedor. No modo de produção capitalista atual, isso é um valor. Nesse princípio do século XXI, a ideia de carreira se insere num modo de produção capitalista e numa formação social específica, a brasileira.

A globalização colabora para a implantação de um novo modelo de sociedade, de carreira e de competência, pois não incide apenas sobre a expertise para a elaboração de novos produtos, mas sobre as relações humanas e o conceito de trabalho, carreira, individualidade, competência e desempenho. A globalização trouxe, para o profissional brasileiro, modelos de competência e desempenho de outras sociedades, cujos padrões de produção e de avaliação, diferentes dos nossos, são tomados como modelos e seguidos fielmente. Essa adesão a padrões globais deve-se ao prestígio que eles têm, oriundos de sociedades consideradas mais desenvolvidas e, portanto, mais "avançadas" que a nossa, e à vinculação do nosso sistema produtivo com o mundial.

Consideradas essas relações entre o modo de produção, as mudanças da tecnologia, o processo de globalização e a transição da gerência para a docência, o texto se propôs a seguinte questão de pesquisa: quais as evidências desses fatores, no discurso desses profissionais e que imagem de si, inclusive no que se refere às competências, este discurso constrói? São, pois, objetivos da pesquisa: indicar os efeitos do modo de produção contemporâneo sobre o profissional, sua carreira e trajetória; identificar as imagens de academia e de organização que ele tem, motivadores da transição e de suas aspirações; caracterizar o profissional que realiza a mudança de carreira e a imagem que si que ele tem.

Parte-se da hipótese de que a mudança de carreira não seria apenas uma decisão pessoal, um desejo de mudança, mas consequência do modelo globalizante de produção, cujo REAd I Porto Alegre - Edição 75 - N 2 - maio/agosto 2013 - p. 301-329 
Luiz Claudio Vieira de Oliveira, Zélia Miranda Kilimnik \& Rafael Parreira de Oliveira grau crescente de competição, de desempenho e de atualização é elemento estressante e desestimulador, indicando que a carreira atingiu certo patamar, o career plateau, que a impede de crescer.

\section{REVISÃO DE LITERATURA}

\subsection{Carreira e competência}

Segundo Porter, a produtividade de um país é atestada pelo padrão de vida, sempre crescente, de seus habitantes e depende da capacidade das empresas de atingir e de manter um alto índice de produtividade, cada vez mais sofisticado, com maior tecnologia, sempre de forma mais eficiente: "As empresas devem melhorar de forma implacável a produtividade dos setores existentes, adicionando características desejáveis, desenvolvendo a tecnologia de seus produtos ou impulsionando a eficiência da produção" (PORTER, 1999, p. 172).

Fleury e Fleury (2003) destacam que empresas globais montam redes interorganizacionais internacionais, cujas estratégicas competitivas serão determinadas pelas competências desenvolvidas. A produtividade de um país e das empresas pode ser estendida à produtividade dos trabalhadores, pressionados por uma exigência nacional e internacional, de quem se exige eficiência, produtividade, tecnologia, sofisticação, num ritmo acelerado (PORTER, 1999; MACIEL, 2002; FLEURY; FLEURY, 2003; AMARO, 2008). A posição de Porter, e dos demais autores, representa uma visão tradicional quanto à produtividade, a ser conquistada a qualquer custo, diferente da postura atual, que considera questões ambientais e a responsabilidade social de organizações e de países.

A partir da Revolução Industrial, em movimentos sucessivos, o processo de globalização se instaurou, abolindo fronteiras e impondo aos estados-nação a ditadura das organizações cujo objetivo, segundo Porter (1999, p. 167), é a produtividade e a competição: “A competitividade de um país depende da capacidade da sua indústria de inovar e melhorar". Esse processo de depuração da globalização teve seu auge durante o chamado Neoliberalismo, a partir do último quarto do sec. XX. Segundo Bresser Pereira (2009), o Neoliberalismo apenas permitiu, a homens e mulheres, a defesa do próprio interesse, transformado em interesse geral pela mão invisível do mercado, agora ampliado pela globalização, que transformou o mundo em um grande mercado, um grande sistema permanentemente integrado.

REAd I Porto Alegre - Edição 75 - N 2 - maio/agosto 2013 - p. 301-329 
Da gerência para a docência: metáforas do discurso de transição

O conceito de competência liga-se ao conceito de competição e obtenção de resultados concretos, relacionando-se ao indivíduo e à organização (PERRENOUD, 1999). De acordo com Brígido (2005), a palavra competência liga-se ao conceito de competir. Competente é quem compete. Ao valorizar a competência, a organização favorece a disputa entre os profissionais para mostrarem mais resultados e serem considerados mais competentes. Competência não é nunca algo adquirido e estável: é algo dinâmico, que se exercita no presente, como reação às solicitações do contexto e ao processo de inovação tecnológica (DREJER, 2002; DUBOIS; ROTHWELL, 2004; ASSUMPÇÃO, 2006; DOLABELLA; BITENCOURT, 2006; RODRIGUES JR.; CABRAL; SOARES, 2006; DUTRA; FISHER; RUAS; NAKATA, 2006; SMITH, 2008; SANTOS; NEPOMUCENO, 2009; LEAL; BANDEIRA, 2009). Castro, Kilimnik e Sant'anna (2008, p. 110), com base em Le Boterf, afirmam que a competência é "[...] contingencial, ou seja, exerce-se em contexto particular, exigindo flexibilidade e ampla capacidade de atualização”.

Segundo Maciel (2002, p. 18), “O modelo de competências profissionais, na verdade, começa a ser discutido no mundo empresarial a partir dos anos oitenta, no contexto da crise estrutural do capitalismo que se configura, nos países centrais, no início da década de setenta”. A superação dos modelos tayloristas e fordistas pelo toyotismo, além das transformações do capitalismo internacional, exigiu das empresas uma adaptação aos novos tempos de concorrência e de aumento da competência, i.e., de sua capacidade de competir. Funcionários deveriam demonstrar excelência, isto é, competência. Para Maciel (2002, p. 18),

a apreensão do conceito de competências e suas implicações no estabelecimento de
novas relações sociais de trabalho deve ser feita [...] principalmente nas
determinações atuais do âmbito capital e trabalho, pois é nesse âmbito que se
definem os usos que se fará da noção de competência.

Silva e Cunha (2002, p. 77), ao analisarem a transição para o século XXI, sob a ótica da sociedade do conhecimento, indicam a relação, exigida pela globalização, existente entre o trabalho e o conhecimento: "A atividade produtiva passa a depender de conhecimentos, e o trabalhador deverá ser um sujeito criativo, crítico e pensante, preparado para agir e se adaptar rapidamente às mudanças dessa nova sociedade." Como a produção e circulação de conhecimento se tornam cada vez maiores, o uso criativo do conhecimento exige melhores desempenho e competência do profissional. Balceiro e Ávila (2003, p. 4) ressaltam as mudanças tecnológicas e a influência do mundo globalizado que "vêm exigindo maior adaptabilidade, competência e capacidade de aprendizagem, tanto das empresas quanto de REAd I Porto Alegre - Edição 75 - Nº 2 - maio/agosto 2013 - p. 301-329 
Luiz Claudio Vieira de Oliveira, Zélia Miranda Kilimnik \& Rafael Parreira de Oliveira seus empregados, além de permanente inovação e aumento da velocidade de realização de seus processos".

Amaro (2008, p. 92) destaca que, no contexto da acumulação flexível, após o modelo fordista e taylorista, cuja ênfase recaía sobre a qualificação, o conceito de competência passa a adquirir novas significações: "iniciativa, flexibilidade, polivalência, multifuncionalidade, cooperação e autonomia". Nunes e Barbosa (2009) acrescentam: flexibilidade mental, capacidade crítica, competência técnica e capacidade inovadora, capacidade para lidar com novas informações, em número maior, mais diferenciadas e com acesso sempre diferenciado.

Reyes et al. (2005) fazem a listagem dos conceitos de competência, desenvolvidos entre 1995 e 2001, indicando a complementaridade entre habilidades, conhecimentos, personalidade, desempenho, repertórios de comportamentos, tecnologias e os resultados da organização. No levantamento feito, foram considerados os seguintes autores: Falconi (1995), Leboyer (1997), Nisembaum (2000), Becker, Huselid e Ulrich (2001), Boog (2001).

Segundo Munck, Munck e Souza (2011), as competências incluem habilidades e disposições que ultrapassam habilidades cognitivas e características da personalidade, podendo ser aprendidas por meio de treinamentos. Esses autores recuperam os modelos de competências propostos por Boyatzis (1982), Kochansky (1997), Spencer e Spencer (2003), Dubois e Rothwell (2004) e Grygoriev (2006), que propõem a criação de um modelo que “[...] delimita e orienta o desenvolvimento desses comportamentos e guia a contratação pelos componentes centrais do trabalho, definidos como preditores de resultados bem sucedidos".

As competências serão aferidas por indicadores comportamentais e têm a função de traçar um caminho para o setor de recursos humanos e para o próprio profissional, estando sujeitas à cultura organizacional: “[...] servem como orientação para a construção de carreiras distribuídas em eixo que traduzem a possível trajetória do indivíduo na organização" (MUNCK; MUNCK; SOUZA, 2011, p. 10, 12).

De acordo com Armstrong (2009), citado por Demo et al. (2011), os modelos de competências influenciam as políticas de gestão de pessoas, no sentido de criar uma referência para as práticas organizacionais e para a atuação dos indivíduos. O que os autores ressaltam é a dificuldade de implantação de um modelo de competências como forma de gestão de pessoas. Frequentemente, não dá conta da realidade (MUNCK; MUNCK; SOUZA, 2011, p. 46), nem da atração e retenção de profissionais (DEMO et al., 2011, p. 35). Chen e Chang (2011) destacam a relação entre a competência individual e a competência organizacional como fundamental para a vantagem competitiva da organização. Para obtê-la, as organizações insistem na adoção de modelos de competências: "Core competence, built REAd I Porto Alegre - Edição 75 - N 2 - maio/agosto 2013 - p. 301-329 
Da gerência para a docência: metáforas do discurso de transição

based on the mission and strategies of the organization, strategically directs the development of human competence in the organization" (CHEN; CHANG, 2011, p. 5743).

Amaro (2008, p. 107) já chamara a atenção para um aspecto interessante e paradoxal da competência, esclarecedor das razões da mudança de carreira: é que a noção de competência, com suas características, liga-se à ausência de prescrição: “A competência ganha espaço exatamente no momento em que se reconhece a impossibilidade de prescrever totalmente a ação dos indivíduos no ambiente de trabalho". A esse respeito, Sant'Anna, Reis e Kilimnik (2006, p. 25) destacaram que a competição empresarial tem duas faces: por um lado, a valorização do capital intelectual das empresas e das competências individuais, importantes para a vantagem competitiva da empresa e,

Por outro lado, observam-se, não raro, relatos acerca da intensificação do volume de
trabalho imposto aos trabalhadores, em decorrência, por exemplo, de sucessivos
processos de enxugamento organizacional; de contínua automatização e rotinização
de funções, aliadas à sofisticação dos mecanismos e formas de controle,
potencializados pelas novas tecnologias adotadas; assim como de elevação das
pressões sobre os trabalhadores, incluindo-se aquelas por contínua atualização
profissional, legitimadas por discursos como os da competitividade,
empregabilidade e competência.

Portanto, a competência sofre os dois influxos: liberação e controle. Quanto menos prescrições, maior a competência; quanto mais prescrições, menor a competência. Torna-se claro que, provavelmente, o profissional não se submeterá a controles, aumento de trabalho e pressões oriundos da organização, se for o profissional competente que apresenta as quinze características apontadas por Richardson et al. (1985), citados por Sant'Anna (2008):

Domínio de novos conhecimentos técnicos associados ao exercício do cargo ou
função ocupada; capacidade de aprender rapidamente novos conceitos e tecnologias;
criatividade; capacidade de inovação; capacidade de comunicação; capacidade de
relacionamento pessoal; capacidade de trabalhar em equipes; autocontrole
emocional; visão de mundo ampla e global; capacidade de lidar com situações novas
e inusitadas; capacidade de lidar com incertezas e ambiguidades; iniciativa de ação e
decisão; capacidade de comprometer-se com os objetivos da organização;
capacidade de gerar resultados efetivos e capacidade empreendedora.

Caso a organização decida pressionar cada vez mais, acabará por sufocar a competência e obrigará o profissional competente a mudar de carreira. Como as organizações adotam ferramentas de gestão cada vez mais prescritivas, como o Enterprise Resource Planning (ERP), acabam por sacrificar a liberdade criadora da competência à possibilidade de controle e de gestão (GRIPA, 2007). Quem opta pela mudança de carreira é aquele que é 
Luiz Claudio Vieira de Oliveira, Zélia Miranda Kilimnik \& Rafael Parreira de Oliveira competente, tanto no sentido de competir, ou seja, de disputar posições, quanto na acepção de ter iniciativa, ser polivalente e autônomo ou, em outras palavras, de não submeter-se às normas da organização. Assim, o profissional opta pela mudança como forma de crescer mais, ter mais espaço próprio e alcançar níveis mais altos, deixando para trás o nível ou platô a que a organização o relegara.

Além disso, a transição de carreira pode ser efetivada, também, pela sensação objetiva e mensurável que o profissional tem de estar estagnado dentro de uma organização, ocupando por vários anos o mesmo nível, ou pela percepção, subjetiva, de que está sendo mantido ou deixado nesse nível. Ambas são vistas negativamente, uma vez que o sucesso numa carreira é indicado pela progressão que se obtém dentro dela (PALMERO; ROGER; TREMBLAY, 2001). Por isso, as duas percepções correspondem ao conceito de career plateau, que pode ser definido como a baixa possibilidade de avanço na carreira. Quando um profissional se encontra nessa posição, isso significa problemas, como impossibilidade de realização profissional, aumento de estresse e redução de satisfação, motivação e performance (ONGORI; AGOLLA, 2009).

Pode-se dizer que há dois tipos de career plateau: o pessoal e o organizacional. O primeiro diz respeito ao profissional que se sente satisfeito com o estágio em que se encontra, que lhe dá segurança e conforto, tendo optado por não crescer na organização. O plateau organizacional refere-se à dificuldade de crescimento dentro da organização (CLARK, 2005). Isso se dá pela impossibilidade de alcançar novos patamares hierárquicos, ou por já ter atingido posições-chave dentro da organização. Se a organização não se preocupa em reduzir seu impacto sobre o profissional (controle, restrições, ausência de oportunidades, empecilhos à criatividade), acaba por colocá-lo no career plateau (HERMAN et al., 2011). Assim, o profissional vê-se obrigado a transitar de uma carreira para outra, cujas características sejam diferentes daquela em que está, mas que lhe permita usar seus conhecimentos e expandir sua criatividade. É o que ocorre quando a opção se faz pela carreira docente.

Ao passar da organização para o mundo acadêmico, o profissional ganha autonomia e maior competência, por continuar ligado (por sua origem ou de fato) ao mercado e por trazer o mercado para a academia. Ao se apresentar como competente (autônomo, com iniciativa, polivalente), mostra-se qualificado para o cargo de professor (pós-graduação e experiência no "mundo real"). O professor se caracteriza como um profissional cuja competência, como foi definida acima, exige flexibilidade e adaptação ao contexto. Para Perrenoud (1993, p. 67), “[...] as profissões que trabalham com pessoas (psicólogos, trabalhadores sociais, professores 
Da gerência para a docência: metáforas do discurso de transição

e outros) convivem com a mudança, com a ambiguidade, o desvio, a opacidade, a complexidade, o conflito".

De acordo com Kilimnik, Sant'Anna, Oliveira e Barros (2008), no texto "Seriam as âncoras de carreiras estáveis ou mutantes? Um estudo com profissionais de Administração em transição de carreira", a transição de carreira, indo do mercado para a academia, caracteriza-se como carreira proteana, acentuada pelo fato de que, na academia, o profissional está sujeito a estímulos, que mudam permanentemente, e a situações variáveis em sala de aula. Segundo Kilimnik, Sant'Anna e Castilho (2008), a carreira proteana é gerenciada pela pessoa, de acordo com sua experiência educacional e de trabalho, e é determinada pelas escolhas pessoais de carreira e autorrealização.

O processo de transição de carreira, como afirmam Kilimnik, Sant'Anna e Castilho (2008), foi influenciado por as empresas terem deixado aos funcionários a autonomia e a responsabilidade pelo planejamento das respectivas carreiras. Da autonomia para o planejamento à mudança de carreira, dentro dos requisitos de competência que o funcionário deve ter, é questão de oportunidade. Segundo Paiva e Melo (2009), professores valorizam, sobretudo, sua autonomia, além do processo interativo da profissão. Rowe e Bastos (2007, p. 13) indicam que, na pesquisa que realizaram sobre docentes de instituições públicas e privadas, “[...] a correlação entre o comprometimento com a carreira e o comprometimento organizacional é positiva e significativa”.

Hanashiro e Nassif (2005) delineiam o perfil do profissional docente como empreendedor e competente em sua área, cônscio de sua situação social e política, aberto ao novo e capaz de tomar decisões rápidas. Mas, "Acima de tudo, aberto ao aprendizado constante, atento à sua capacidade de transmissão do conhecimento, habilidoso nas críticas e contextualizações das relações socioculturais e com uma desenvoltura investigatória aguçada" (HANASHIRO; NASSIF, 2005, p. 47). É por se enquadrar nessa expectativa que o profissional faz a transição da gerência para a docência.

\subsection{Análise do discurso}

Em 1916, nasce a Linguística contemporânea, com o livro Curso de Linguística Geral, de Ferdinand de Saussure, que deu à Linguística o status de ciência e revolucionou o estudo da linguagem. Saussure (1970) foi o responsável pela criação dos conceitos de signo, de valor 
Luiz Claudio Vieira de Oliveira, Zélia Miranda Kilimnik \& Rafael Parreira de Oliveira e de dupla articulação da linguagem. O primeiro significa uma relação entre uma imagem acústica (um som) e um conceito, ou melhor, entre um significante e um significado:

$$
\text { signo }=\frac{\text { anceite }}{\text { imagem acústica }} \text { ou signo }=\frac{\text { aignifieante }}{\text { signifieado }} \text {. O importante é lembrar que essa }
$$

equivalência entre Significante e Significado nos dá o sentido da palavra, como se vê no dicionário. As palavras são usadas em sentenças, ou seja, conjuntos de palavras, em que os sentidos originais das palavras podem mudar. Essa nova significação, dada pela relação entre os signos, se sobrepõe à antiga, dicionarizada, incluindo-a e ampliando-a. Isso é o que Saussure chama de valor, tal como se representa abaixo:

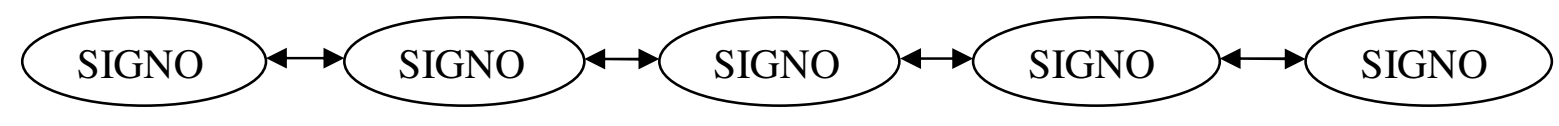

Figura 1 - Valor dos signos a partir do eixo sintagmático (sequência de signos) Fonte: SAUSSURE, 1970, p. 133.

Foi o conceito de dupla articulação que permitiu à Linguística criar, para as Ciências Humanas e para as Ciências Sociais, uma metodologia de análise. Um continuum (uma sentença) pode ser dividido em unidades menores dotadas de sentido: os signos (palavras). Cada signo pode dividir-se em unidades menores: os sons. Cada unidade da frase conserva sua independência, sendo usada em outros contextos, isto é, em outras sentenças; cada som também conserva sua independência, sendo usado em outros contextos, isto é, em outras palavras.

Este é o caráter econômico da linguagem: poucos sons (representados basicamente por 26 letras) podem compor milhares de palavras; com as palavras geradas, produzem-se milhões de sentenças. As unidades mínimas da linguagem são entidades opositivas, relativas e negativas: sua significação advém da relação de oposição e de diferença que mantêm com outras unidades. Na língua, importa a diferença e não a semelhança.

O limite da Linguística tradicional é a sentença. Os textos (conjuntos de sentenças que se relacionam pelo conteúdo tratado) ${ }^{1}$ foram analisados pela Retórica e pela Poética, e passaram a ser considerados pela Estilística, pela Teoria Literária, pela Análise do Discurso e por outras correntes estruturalistas que, a partir dos anos sessenta, aplicaram os achados linguísticos a objetos mais amplos que a sentença.

\footnotetext{
${ }^{1}$ Dada a complexidade do conceito de texto, preferimos defini-lo apenas dessa forma ampla.
}

REAd I Porto Alegre - Edição 75 - Nº 2 - maio/agosto 2013 - p. 301-329 
Da gerência para a docência: metáforas do discurso de transição

A linguagem tem um caráter social, prescritivo e autoritário. Inclui o sujeito numa estrutura social - numa organização - ao dar-lhe acesso a essa mesma linguagem e a uma representação do mundo. Mas lhe dá certa liberdade, permitindo-lhe criticar a linguagem e produzir o seu próprio discurso. O sujeito não é apenas uma vítima passiva da estrutura social e discursiva, mas um agente de sua própria inserção social e de seu próprio discurso.

O procedimento básico para a análise de qualquer discurso é identificar suas unidades mínimas: elas se combinam para formar unidades maiores, como as palavras se juntam para formar frases e como os sons (fonemas) se reúnem para formar palavras. A dificuldade está em que as unidades mínimas não existem previamente ao discurso: devem ser identificadas a cada análise. O discurso não se revela de imediato ao seu analista: requer uma leitura atenta e minuciosa. Há uma camada visível do texto, o dito, e uma outra, o não dito, cujo sentido, presente no texto, não está evidente. Essa latência do não dito deve ser percebida pelo analista, e só o será se houver olhos para ver o que jaz nas entrelinhas, o entre dito. Nunca há uma leitura errada do texto. Há leitura em camadas, superficial ou profunda, dependendo do grau de atenção do analista.

A atual Análise do Discurso provém de tradição filosófica europeia, de Saussure, Marx e Freud, cujas obras reviram formas tradicionais de encarar a linguagem, o sujeito e a economia, três sistemas simbólicos. Essa tradição permanece com Lacan, que relê Freud, e se desenvolve sob os influxos do Estruturalismo, por autores como Algirdas Julien Greimas, Roland Barthes, Oswald Ducrot, Émile Benveniste, Tzevetan Todorov, Michel Foucault, Michel Pêcheux, Roman Jakobson (DOSSE, 1993) e Patrick Charaudeau (1993, 2006, 2010).

Autores e teorias moldaram essas reflexões, denominadas como Análise do Discurso Francesa (ADF). Todos coincidem ao considerar que o real não é evidente e translúcido, mas opaco, sempre manifestado por um discurso constituído por signos e por símbolos. Outra característica básica da $\mathrm{ADF}$, hoje, é a pragmática, ou seja, a situação concreta de comunicação em que os sujeitos do discurso se colocam. Segundo Charaudeau (2010, p. 24), o problema da comunicação não está no que é dito explicitamente, mas na associação da linguagem a um contexto:

\footnotetext{
A finalidade do ato de linguagem [...] não deve ser buscada apenas em sua configuração verbal, mas, no jogo que um dado sujeito vai estabelecer entre esta e seu sentido implícito. Tal jogo depende da relação dos protagonistas entre si e da relação dos mesmos com as circunstâncias de discurso que os reúnem.
} 
Luiz Claudio Vieira de Oliveira, Zélia Miranda Kilimnik \& Rafael Parreira de Oliveira

\section{METODOLOGIA}

\subsection{A opção metodológica}

Para a análise dos discursos dos profissionais entrevistados, que realizaram a transição de carreira, da gerência para a docência, utilizou-se a metodologia da Análise do Discurso Francesa (ADF), previamente conceituada.

\subsection{Coleta de dados}

A coleta de dados foi realizada com vinte e dois professores universitários, de variadas formações (Administração - 12; Engenharia - 3; Economia - 2; Biologia, Comunicação Social, Advocacia, Psicologia, Arquitetura - 1) com cursos de especialização e, ou, mestrado. Há profissionais ligados apenas à atividade docente e outros que conciliam o trabalho nas organizações e na academia. A seleção dos sujeitos da pesquisa se fez por acessibilidade e por "bola de neve". O critério para seleção foi o de terem feito a transição, da gerência em organizações (empresas estatais ou privadas) para a docência em faculdades ou universidades, total ou parcialmente. Todos os profissionais trabalhavam, no momento das entrevistas, em Belo Horizonte, Minas Gerais.

Os pesquisadores realizaram entrevistas não estruturadas, individualmente, a partir de um roteiro básico, elaborado a partir da contribuição da professora Joanne Duberley, da University of Birmingham, pesquisadora do tema transição de carreira (DUBERLEY; COHEN; LEESON, 2006a; DUBERLEY; COHEN; LEESON, 2006b). As respostas das entrevistas e as discussões do grupo focal foram gravadas e, posteriormente, transcritas.

\subsection{Processo de análise}

Após exame das entrevistas transcritas, aplicou-se a metodologia da Análise do Discurso Francesa (ADF) e seus desdobramentos teóricos no Brasil. A ADF não se interessa apenas pelos aspectos linguísticos (gramaticais) do texto, mas pela sua discursividade: sua semântica e sua relação com outros aspectos contextuais (pragmáticos).

Como o homem se expressa por meio da linguagem simbólica, que se coloca sempre no lugar de "outra coisa", compreender o uso simbólico da linguagem é importante para conhecer as relações que os homens estabelecem com outros homens e as referências feitas à realidade. A atividade social humana é mediatizada pela linguagem. Analisá-la e compreender seus sentidos, sempre mutáveis, tornou-se fundamental para a Literatura, a Psicologia, a Sociologia, a Filosofia, por exemplo, e, mais recentemente, para a Administração. 
Da gerência para a docência: metáforas do discurso de transição

Para lidar com um objeto instável, como um discurso, é preciso contar com um instrumento com uma base teórica sólida, mas com uma operacionalização sempre ad hoc. A significação do texto ultrapassa o somatório do sentido de cada signo linguístico e do sentido que advém das relações sintáticas entre signos. Inclui as relações, explícitas e implícitas, que cada signo estabelece com os demais, quanto à significação pretendida pelo autor e quanto à capacidade de percepção do leitor. Se a linguagem, e os textos que produz, fossem imóveis, estáticos, sua leitura seria única, definitiva. Como, num texto, tudo (autor, signos, leitor) está em movimento, as leituras irão também variar no tempo e no espaço, uma vez que a interpretação irá variar de acordo com a formação, a informação, a classe social e a visão de mundo do leitor.

A partir da leitura minuciosa das entrevistas, estabeleceram-se dezessete categorias, com emprego de critérios ad hoc, que forneceram elementos para analisar e comparar cada entrevista. As categorias surgiram dos objetivos iniciais da pesquisa, de indicar os efeitos do modo de produção contemporâneo sobre o profissional, sua carreira e trajetória; identificar as imagens que ele tem, de academia e de organização, motivadores da transição e de suas aspirações; caracterizar o profissional que realiza a mudança de carreira e a imagem que si que ele tem. O estabelecimento de categorias é técnica básica para qualquer análise discursiva.

Levantaram-se as seguintes categorias: a carreira no mercado; ambiente acadêmico versus ambiente corporativo; avaliação do trabalho como docente; conflito ético; docência na graduação - desafios; docência na pós-graduação (mestrado); exercício da atividade corporativa e da docência; habilidades para a academia; habilidades para a corporação; identidade; metáforas; motivos para a transição; o ensino na graduação e na pós-graduação; mestrado e processo de transição; qualidade de vida e de trabalho; realização na academia; trajetória profissional.

Em seguida, identificaram-se todos os fragmentos relativos às categorias, alguns pertinentes a várias delas. Fez-se, então, uma síntese do conteúdo das falas relativas a cada categoria. Após esse trabalho de análise, passou-se ao exame do novo conjunto, com a finalidade de, progressivamente, chegar-se a uma síntese do material obtido. As categorias foram agrupadas em quatro conjuntos:

1) carreira e organização, englobando as categorias "a carreira no mercado" e "habilidades para a corporação";

REAd I Porto Alegre - Edição 75 - Nº 2 - maio/agosto 2013 - p. 301-329 
Luiz Claudio Vieira de Oliveira, Zélia Miranda Kilimnik \& Rafael Parreira de Oliveira

2) carreira e academia, que inclui "docência na graduação - desafios"; "docência na pós-graduação (mestrado)"; "habilidades para a academia"; "o ensino na graduação e na pósgraduação" e "avaliação do trabalho como docente"

3) transição para a academia, que incorpora "ambiente acadêmico versus ambiente corporativo"; "conflito ético"; "exercício da atividade corporativa e da docência";

4) motivos para a transição, composto por "motivos para a transição"; "conflito ético"; "identidade"; "metáforas"; "qualidade de vida e de trabalho".

Esses conjuntos representam uma condensação e um afunilamento da análise, mas não serão vistos isoladamente, pois se recobrem. São quatro conjuntos cuja importância advém, precisamente, de seu número reduzido, indicando que os entrevistados se prenderam a esses conjuntos, os quais se tornaram elementos fundamentais para nossa análise.

\section{RESULTADOS E DISCUSSÃO}

Os quatro conjuntos de categorias (Carreira e organização; Carreira e academia; Transição para a academia; Motivos para a transição) se interpenetram. O discurso dos entrevistados coincide: todos eles conquistaram uma situação vitoriosa no mundo das organizações, em que demonstraram competência, tal como definido pela literatura. Uma vez que a competência supõe autonomia e a construção de uma identidade própria, a submissão às prescrições das organizações passou a ser problemática, por entrar em conflito com a noção de competência, valorizada ou exigida pelas próprias organizações.

Eu tenho uma personalidade muito criativa: gosto de criar, gosto de inovar, e lá eu não estava podendo fazer esse tipo de atividade porque vem tudo pronto. Você recebe todos os procedimentos e você não pode inovar. Você tem simplesmente de replicar como eles mandam, então eles são os corretos. (Depoente 3)

[...] fiquei três meses, não aguentei o autoritarismo e aí eu decidi que não queria mais aprender eu queria ensinar [...] (Depoente 9).

A empresa não vê com bons olhos pessoas muito críticas [...] (Depoente 10)

[...] o que me levou a mudar a carreira foi a falta de oportunidade de ascensão que eu estava vendo dentro da instituição [...] eu vi que a carreira era promissora e que dependia unicamente da própria pessoa, do esforço da própria pessoa[...]; (Depoente 12)

Eu acho também que as empresas modernas, contemporâneas, elas são, elas agem de uma forma muito turbulenta, muito assustadora como que elas manipulam aquilo que está dentro dela lá, principalmente pessoas [...] (Depoente 18)

[...] eu percebi que o meu horizonte de desenvolvimento pessoal dentro da área em que eu estava atuando me parecia restrito. (Depoente 20)

REAd I Porto Alegre - Edição 75 - Nº 2 - maio/agosto 2013 - p. 301-329 
Da gerência para a docência: metáforas do discurso de transição

Então, eu já tava num momento em que aquele trabalho me trazia sofrimento (...) no domingo, que eu imaginava era segunda-feira, era como se eu estivesse indo para uma guilhotina. (Depoente 21)

A percepção sobre o trabalho nas organizações revela uma constante pressão sobre o profissional, manifestada em palavras como: competitividade, pressão, pressão por resultados, ambiente tumultuado, ausência de comunicação entre setores, incerteza, inexistência de plano de carreira, avaliação de desempenho tendenciosa, duplicidade de critérios, estresse, conflito, deslealdade, insatisfação, carga horária pesada e oscilante, impactos negativos na vida familiar, desgaste de saúde, estafa, doenças psicossomáticas, síndrome do pânico, manipulação, assédio moral, metas exigentes:

[...] o reconhecimento não vem em remuneração, ele vem primeiro em permanência no próprio emprego, [...] É uma pressão diária [...] (Depoente 1)

[...] Na iniciativa privada você depara com um nível de competição de exigência de resultados a qualquer preço. [...] As desvantagens que eu vivi são principalmente ligadas às questões de stress, conflitos muito grandes, existem conflitos muito grandes. Questão de competitividade, deslealdade que tornam o mercado, digamos assim, que às vezes não dá satisfação em trabalhar em certos processos [...] (Depoente 4)

Às vezes tinha semana que eu trabalhava 14 a 16 horas por dia [...]; (a dificuldade) era ter essa instabilidade de jornada. (Depoente 6)

Ganhei cinco stenter e duas pontes. Porque eu sempre fui totalmente comprometido com o que eu fazia. Na história da companhia nesses 30 anos nenhum outro colega no mundo teve a mesma performance que eu, porque nesses trinta anos eu fui o único que sempre cumpri minha cota. (Depoente 8)

As metáforas sobre o mundo empresarial revelam a instabilidade que contém e a insegurança que gera nos profissionais, e assinalam a simbiose entre o funcionário e a organização. O profissional se sente respaldado pelo "sobrenome da empresa", que lhe concede identidade. Ter o mesmo sobrenome significa ter paternidade, ascendência e, de certa forma, nobreza, por compartilhar daquele sobrenome que distingue e qualifica. Pertencer a empresas de sucesso, como $\mathrm{X}$ ou $\mathrm{Y}$, é um rótulo que o profissional ostenta com prazer. A perda da identidade corporativa implica em "ficar solto no mundo", porque sair da empresa significa "perder, literalmente, a mãe". As metáforas paterna e materna revelam o vínculo umbilical entre profissional e empresa e, ao mesmo tempo, que sua identidade e nome não são seus: são da organização.

As exigências do mundo empresarial são muitas e permanentes. Nele, "o ótimo é inimigo do bom", e você pode "ser engolido", passando a estar no "inferno". Se você não é 
Luiz Claudio Vieira de Oliveira, Zélia Miranda Kilimnik \& Rafael Parreira de Oliveira "top de linha", você está fora. Os dois tipos de metáforas opõem dois espaços: alto (sucesso, top de linha) e baixo (ser engolido, estar no inferno). Esses últimos remetem a lugares baixos e negativos (ser deglutido, desaparecer, ser punido para sempre). Para manter-se no topo, é preciso ser "pessoa com o pé no chão", ou seja, ter audácia para alcançar seus objetivos, ter planejamento, raciocínio e, por que não, frieza para enfrentar os desafios, representada pela metáfora "quebrar regras", que não significa ir contra a estrutura do mundo empresarial.

Ao contrário, o mundo empresarial exige que as pessoas não interfiram em áreas que não as próprias, de formação. Por isso, não "vê com bons olhos" quem extrapola a própria competência e "dá pitaco" sobre atividades alheias. Essa manutenção de limites possivelmente se deva à divisão de tarefas e obrigações e à tentativa de evitar a concorrência entre profissionais, uma vez que o mundo empresarial é "briga de foice no escuro", onde é “cada um por si e Deus por todos". Por isso, "a coisa tem que estar redondinha”, funcionando perfeitamente.

Para que se tenha uma "carreira meteórica" no mundo empresarial, é preciso, além de aprender a sair ileso da briga de foice e a enfrentar a "guilhotina", que o profissional tenha "a cabeça nas nuvens e pés pregados no chão" e apresente no currículo "bons quilômetros rodados". A metáfora automobilística diz respeito à experiência, ao pé no chão, à aderência ao terreno e, também, ao tempo de profissão.

É interessante notar que foice e guilhotina têm lâminas que podem separar a cabeça de alguém. Se essa pessoa já tem a cabeça nas nuvens e os pés no chão, talvez consiga sobreviver, pois já fez, por si mesma, a separação, mas com intuito de preservar a união. A metáfora "cabeça nas nuvens e pés no chão" estabelece uma separação entre a prática (pés no chão) e o ideal (cabeça nas nuvens), o que talvez explique a mudança de carreira: quando a cabeça predomina sobre os pés, o profissional tende a transformar sua carreira. Quando a adesão (ou aderência) às práticas empresariais (quilômetros rodados) é suplantada pelo idealismo, é o momento de tentar outra experiência profissional.

Contrastando com a avaliação da carreira na organização, referindo-se à diferença entre organização e academia, destacam-se as frases: "Para mim o mundo acadêmico era um norte” (Depoente 19); “A sala de aula é uma coisa mágica, eu sou apaixonado com a sala de aula" (Depoente 5); e "Hoje em dia eu estou no céu e eu estava no inferno" (Depoente 13). Apesar disso, outros depoentes destacam que a academia não tem gestão, não tem velocidade na tomada de decisões nem planejamento estratégico, nem se vê como um negócio, reiterando as conclusões de Hanashiro e Nassif (2006). Os demais professores se veem como deuses e 
Da gerência para a docência: metáforas do discurso de transição

são inflexíveis, sem abertura para o novo, desqualificando a prática e valorizando apenas a teoria, principalmente "o que a gente traz do mundo coorporativo" (Depoente 7).

Sente-se falta da avaliação da organização. Apesar de provocar estresse, é também reasseguradora e estimulante: caracteriza o perfil do profissional, indica-lhe seu papel e o posiciona em relação aos demais profissionais: “um pouquinho de pressão me dá um tesão enorme" (Depoente 10). A avaliação se relaciona com a carreira (e com a competência), mas é praticamente inexistente na academia (HANASHIRO; NASSIF, 2006; ROWE; BASTOS, 2007). Um dos depoentes reclama da falta de avaliação na escola em que atua e destaca a importância da avaliação para o professor: "[...] Tem sete meses que eu estou na direção e não houve avaliação ainda... não houve um feedback avaliativo com pontuação" (Depoente 3).

Outro contrasta as diferentes avaliações: “[...] a avaliação, dentro da organização, é o seu gerente, é a pessoa que tem relação direta com você, são os seus pares que te avaliam, você se avalia [...] e aqui a gente não tem esse parâmetro, então eu acho fraquíssimo o sistema, porque ele não permite que eu me avalie (Depoente 9). A avaliação discente é algo positivo, apesar de problemática: "Nós que fomos alunos também, sabemos: se eu for o líder na sala e eu quiser detonar o professor, eu faço a turma detonar o professor e o professor pode ser um excelente professor. Então avaliação de aluno é o menos importante nessa história (Depoente 17). Há depoentes que destacam a avaliação acadêmica como mais extensa e profunda que a avaliação da organização, uma vez que, na academia, é preciso produzir intelectualmente, dando aulas e escrevendo artigos.

Os alunos de pós-graduação são mais velhos, mais maduros, mais interessados, tornando as aulas mais fáceis e prazerosas: "o que te permite ter uma troca muito mais rica" (Depoente 22). Além disso, têm experiência de mercado, o que facilita a aprendizagem e aumenta o interesse. Apesar de haver uma mudança, para pior, no perfil dos alunos de pósgraduação, é importante a experiência de mercado do professor: "[...] é fundamental você ter experiência prática também aliada com a experiência acadêmica" (Depoente 5). Já os alunos de graduação apresentam baixo nível, são desmotivados, não leem, são descomprometidos: “A grande maioria não percebe que eles tão ali sendo formados, se formando para ser um profissional naquela área de competência para que ele se propôs, né” (Depoente 17)

O que perpassa em todos os depoimentos é a ideia de que a sala de aula é "mágica", um espaço diferenciado em que se cumpre uma missão, pela qual haverá "reconhecimento perpétuo" por parte dos alunos. O espaço docente é um ambiente onde há possibilidade para leitura, pesquisa, embasamento teórico, atualização permanente, reflexão.

REAd I Porto Alegre - Edição 75 - N² 2 - maio/agosto 2013 - p. 301-329 
Luiz Claudio Vieira de Oliveira, Zélia Miranda Kilimnik \& Rafael Parreira de Oliveira

Uma das depoentes, mesmo afastada por licença maternidade, foi avaliada, porque a coordenação do curso a julgava "comprometida". Essa mesma depoente declara: "eu tenho muito orgulho de minhas avaliações". O compromisso da professora é o compromisso que todos acreditam ter com a docência e que os faz participar das atividades escolares integralmente. A fala que melhor expressa o sentimento dos professores é a seguinte:

\footnotetext{
O que facilita o desempenho da minha atribuição atual de docente é o fato de eu acreditar que isso é uma forma de construir um sonho que eu acredito que é melhor para a humanidade, então o que eu faço é por acreditar em uma missão, eu não vejo a docência como uma forma de ganhar status ou uma forma de ganhar dinheiro ou uma forma de ganhar uma outra coisa qualquer; eu vejo a docência como a única forma que eu consigo contribuir para a melhoria da sociedade; esse é o grande facilitador porque eu faço aquilo que eu acredito que eu estou fazendo bem, eu faço aquilo que eu acredito que, para um conceito meu, é para uma sociedade melhor esse é o grande facilitador (Depoente 11).
}

O fragmento acima repercute uma imagem estereotipada do professor, como aquele que tem a missão de formar a juventude para, por meio dela, mudar a sociedade. A missão sagrada liga-se à crença em uma sociedade melhor. Apesar do comprometimento que se observa, ressalte-se a frase: “[...] nós, de fora do mundo acadêmico" (Depoente 9), que indica haver uma lacuna e uma diferença entre mundo corporativo e acadêmico. Por isso, há a ideia de que, quando se vem do mundo corporativo, pode-se "passar a experiência e oxigenar a geração que vem aî" (Depoente 17); ou "dar mais consistência às aulas” (Depoente 22).

O mundo acadêmico é comparado ao "mundo da carochinha". Isso tem dois sentidos básicos: é o lugar onde tudo é possível, onde os desejos se tornam realidade, mas é também o lugar que não existe, o espaço da utopia. Apesar de ambos os significados oporem o mundo acadêmico ao empresarial, há consciência de que não são locais muito diferentes, pois os dois têm a "fogueira das vaidades", quando os egos incham. A imagem do fogo permanece na metáfora da "prova de fogo", que consiste na indicação do profissional para outras instituições, indicando seu bom desempenho.

A imagem do mundo acadêmico é diferente da do mundo empresarial. Enquanto este é “inferno", o primeiro é "céu". A imagem positiva transparece em: "tapete vermelho", significando o status que o professor tinha: "Deus no céu, professor na terra". Se o mundo acadêmico é céu e o professor é o representante de Deus, isso dá a ele uma função messiânica: "ter uma missão", "mudar o mundo", "marcar, indelevelmente, a alma do aluno", "construir um sonho". Essa divinização do mundo acadêmico equivale à cabeça nas nuvens e à necessidade de estar no alto, próximo a Deus, liturgicamente dando aula (tapete vermelho). 
Da gerência para a docência: metáforas do discurso de transição

O mundo acadêmico é o "mundo do conhecimento e das ideias", enquanto o empresarial é o "mundo do mercado". São aspectos que se opõem, como céu e inferno. O mundo das ideias, desde Platão, é o centro e a origem de tudo, de onde a matéria (o mercado) provém. Entretanto, o "mundo ideal" seria a combinação da academia com a empresa.

A idealização da figura do professor e de seu trabalho (sua missão) corresponde ao entendimento de como deve atuar: "dar o caminho das pedras" para os alunos é metáfora que dá sequência às imagens religiosas. Os alunos devem ser vistos como pessoas que trazem "bagagens diferentes", que não são "máquinas ou computadores", mas profissionais em formação. Por outro lado, os alunos são menos compromissados que os colaboradores de uma organização. Para dar uma aula interessante tem-se, com exagero, "que dançar a dança do ventre, porque rebolar não adianta". "Quanto mais "horas de voo" o professor tem, mais aumentará seu "peso" acadêmico, porque "a gente planta, a gente colhe".

Assim, deve-se fazer "a busca dolorosa pelo conhecimento". Para ser professor, é preciso que a vocação "esteja no sangue" e que se seja "100\% professor", além de dedicar-se totalmente ao mundo acadêmico, colocando todos "os ovos numa cestinha", metáfora que indica cálculo, planejamento, ordenação racional do conhecimento.

\section{CONCLUSÃO}

Como se colocou no primeiro objetivo da pesquisa, espera-se ter deixado claro que discursos mostram que o mundo organizacional sofre os efeitos da globalização, exigindo competência dos profissionais para que as organizações possam competir cada vez mais arduamente. Isso se reflete sobre a carreira e o desempenho desses profissionais, submetidos a uma estrutura de gestão de pessoas e de carreiras, sempre mais rígida, que exige profissionais cada vez mais criativos e competentes e, ao mesmo tempo, cada vez mais submissos às normas e critérios organizacionais (ZARIFIAN, 2001; PORTER, 1999; MACIEL, 2002; FLEURY; FLEURY, 2003; AMARO, 2008; SMITH, 2008; CASTRO; KILIMNIK; SANT'ANNA, 2008; SANTOS; NEPOMUCENO, 2009; LEAL; BANDEIRA, 2009). Como se referiu anteriormente, o alto nível de exigência de competências e o alto grau de restrições podem levar a um career plateau, forçando o profissional a buscar novos espaços para se manifestar de forma criativa (PALMERO; ROGER; TREMBLAY, 2001; CLARK, 2005; ONGORI; AGOLLA, 2009). 
Luiz Claudio Vieira de Oliveira, Zélia Miranda Kilimnik \& Rafael Parreira de Oliveira

Pretende-se também ter atingido o segundo objetivo proposto, o de identificar as imagens de academia e de organização que os profissionais têm, motivadores da transição e de suas aspirações, uma vez que os discursos analisados separam de maneira clara os dois espaços. Os discursos caracterizam a academia como um lugar utópico e ingênuo. Como um locus amoenus, é o espaço da qualidade de vida, perseguida pelos que deixaram o mundo empresarial: convivência com a família, horário flexível, vida pessoal, desafios trazidos por disciplinas diferentes, menos viagens e satisfação, em vez de remuneração maior. É um lugar onde se pode ler, aprender, pesquisar, embasar-se teoricamente, trocar experiências, assumir desafios, enfrentar mudanças, crescer intelectualmente. É também onde se pode mudar os alunos, a sociedade e o mundo. Há oportunidade de aprendizado, de troca, de livre-arbítrio. É ainda o espaço onde a competência individual é possível, tal como definida por Kilimnik, Castilho e Sant'anna (2006): um misto de conhecimentos, aprendizagem permanente, criatividade, inovação, comunicação, relacionamento pessoal, trabalho em equipe, autocontrole, visão de mundo ampla, iniciativa, comprometimento e produção.

A visão negativa caracteriza-se pela resistência com que as novidades, trazidas do mundo empresarial, são recebidas pelos professores cuja origem é apenas acadêmica. Ao contrário das organizações, a academia não tem ferramentas de gestão e de avaliação, muitas vezes delegadas aos alunos. Não há planejamento estratégico, nem visão do negócio; a academia é distanciada do mundo corporativo; os egos são inflados e a competição, como nas organizações, é desleal; professores julgam-se donos da verdade e deuses; não há trabalho em equipe, mas individual; professores trabalham sós; valoriza-se a teoria, mas não a prática; as decisões são lentas e burocráticas; o professor iniciante não é orientado.

Academia e organizações são mundos separados. A ponte entre eles será feita por quem conseguir fazer a transição, mantendo "um pé" em cada setor. Apesar de não ser afirmado explicitamente, os discursos valorizam o mundo empresarial em relação ao mundo acadêmico. O mundo empresarial tem planos, métodos, visão de negócio, ferramentas de gestão, trabalho em equipe, exigências, cobranças, metas, aferição de produtividade: o mundo empresarial exige uma competência, que é reasseguradora, principalmente por atribuir, a cada indivíduo, um lugar e um papel definidos.

Por outro lado, o profissional competente, que não conseguiu mais suportar as pressões e os padrões empresariais, é quem fez a transição para a docência. Esse profissional competente, nostálgico do mundo empresarial, vai fazer com que os alunos transitem para esse mundo "real", oposto ao mundo "da carochinha", que é a academia. Apesar de estarem 
Da gerência para a docência: metáforas do discurso de transição

na academia, os profissionais valorizam a organização e, ao mesmo tempo, criam, discursivamente, uma imagem supervalorizada de si mesmos.

Assim, o terceiro objetivo, o de caracterizar o profissional que realiza a mudança de carreira e a imagem que si que constrói, também foi atingido. Tanto o profissional quanto a imagem são bastante positivos e utópicos. Caracterizando o professor, os entrevistados se caracterizaram. Didaticamente, o professor é um profissional que prepara e ministra aulas que respeitam os alunos, produzindo material de qualidade; incentiva, estimula, motiva, contagia, empolga os alunos e interage com eles; preocupa-se com a aprendizagem e percebe necessidades didáticas para passar informações. Nas aulas, é um mentor, adorado e respeitado pelos alunos; cumpre uma missão, pois realiza "uma atividade social pura": "dá a mão e fala: vamos chegar ao sucesso".

Pessoalmente, além do conhecimento do conteúdo, aprende com a experiência, atualiza-se, estuda muito, gosta de leitura e lê bastantes textos teóricos, recicla-se pessoal e didaticamente. Suas qualidades compreendem aceitar o outro, ser humilde, disciplinado, metódico, inteligente, maduro, perfeccionista, visionário e um eterno aprendiz. Considera o magistério uma função nobre, condizente com missão que desempenha. Mais: sabe ouvir, sabe falar bem, tem excelente comunicação verbal, escrita e visual, e é carinhoso, carismático, atencioso. Este professor rompe paradigmas, é criativo, enfrenta situações inesperadas e de risco, é empreendedor e busca novidades sem perder o foco. É gestor de ensino, questionador, dono do seu mundo e controla os próprios indicadores. Considera o magistério como um dom.

Profissionalmente, é um profissional que deve manter laços com o mundo empresarial, trazendo para a academia o lado prático da vida, dando aos alunos a prática, "que é o que precisam saber". Não se perde nos livros, desconectando-se da realidade. Precisa estar atualizado com o que se passa, no país e no mundo, com os negócios e apresentar cases para os alunos. Precisa manter seus relacionamentos no mundo empresarial. Não pode ser teórico, mas prático. A prática distingue o profissional, que fez a transição, daquele que é só acadêmico.

A transição de carreira é provocada pelas relações de produção contemporâneas, pelas mudanças na tecnologia, que exigem uma atualização permanente, e pela globalização, cujas características obrigam as empresas a um processo intenso de competição e a adquirir uma competência crescente. Por outro lado, a transição é feita por profissionais, competentes em suas organizações, que atingiram os limites, o career plateau, e são resistentes às prescrições. A imagem de si que constroem, ao caracterizar o professor, coincide com as características REAd I Porto Alegre - Edição 75 - Nº 2 - maio/agosto 2013 - p. 301-329 
Luiz Claudio Vieira de Oliveira, Zélia Miranda Kilimnik \& Rafael Parreira de Oliveira apontadas para a competência: aprendizagem, criatividade, inovação, comunicação, visão de mundo e iniciativa.

A transição da gerência para a docência é um processo que foi observado em cursos de de Graduação em Administração. É interessante que exista, uma vez que os alunos estão sendo formados para o mercado. A visão prática e objetiva é importante para a formação dos futuros profissionais e para atender as demandas existentes. Por outro lado, cabe às escolas e Universidades a formação ampla de seus alunos, a fim de que adquiram uma formação que extrapole o mercado e suas necessidades, ainda que os leve em consideração. A competência desses docentes e sua capacidade de ultrapassar limites e prescrições é um exemplo importante a ser passado para a academia. Deve haver, portanto, por parte das instituições de ensino, uma receptividade maior e mais profunda desses profissionais, alinhados com o mercado e com o que se supõe ser o mais moderno; ao mesmo tempo, faz-se necessária uma compreensão das tradições e características escolares, por parte desses profissionais. Assim, haverá uma troca mútua de conhecimentos e de experiências, efetivando-se a transição da gerência para a docência e, desta, o salto para um saber mais profundo, que una as duas dimensões.

\section{REFERÊNCIAS}

AMARO, Rubens de Araújo. Da qualificação à competência: deslocamento conceitual e individualização do trabalhador. RAM - Revista de Administração Mackenzie, São Paulo, v. 9, n. 7, p. 89-111, 2008.

ARAÚJO, ROMILDA Ramos; SACHUK, Maria Iolanda. Os sentidos do trabalho e suas implicações na formação dos indivíduos inseridos nas organizações contemporâneas. Revista de Gestão USP, São Paulo, v. 14, n. 1, p. 53-66, jan./mar. 2007. Disponível em: <http://www.revistasusp.sibi.usp.br/pdf/rege/v14n1/v14n1a5.pdf>. Acesso em: 2 abr. 2010.

ARMSTRONG, M. Armstrong's handbook of human resource management practice. $2^{\text {nd }}$. ed. London: Kogan Page, 2009 apud DEMO, Gisella et al. Políticas de gestão de pessoas no novo milênio: cenário dos estudos publicados nos periódicos da área de Administração entre 2000 e 2010. RAM - Revista de Administração Mackenzie, São Paulo, v. 12, n. 5, p. 1542, set./out. 2011. Disponível em: <http://www.scielo.br/scielo.php?pid=S1678$69712011000500002 \&$ script=sci_abstract\&tlng=pt>. Acesso em: 25 jun. 2012.

ASSUMPÇÃO, Joubert. O papel das competências técnico-organizacionais na estratégia organizacional: evidências de cinco organizações não governamentais no Rio de Janeiro (1996-2004). In: ENCONTRO DA ASSOCIAÇÃO NACIONAL DE PÓS-GRADUAÇÃO E

REAd I Porto Alegre - Edição 75 - Nº 2 - maio/agosto 2013 - p. 301-329 
Da gerência para a docência: metáforas do discurso de transição

PESQUISA EM ADMINISTRAÇÃO, 30., 2006, Salvador. Anais... Salvador: ANPAD, 2006. 1 CD-ROM.

BALCEIRO, Raquel Borba; ÁVILA, Giovani Manso. A gestão de pessoas para o profissional do conhecimento. In: KM-BRASIL - CONGRESSO BRASILEIRO DE GESTÃO DO

CONHECIMENTO, 2., 2003, São Paulo. Anais... São Paulo: KM-BRASIL, 2003. Disponível em:

<http://www.ibmex.com.br/artigos/Gestao_de_pessoas_para_o_profissional_do_conheciment o.pdf >. Acesso em: 19 mar. 2010.

BARROS, Alice Monteiro de. Curso de Direito do Trabalho. 3. ed. rev. e ampl. São Paulo: LTR, 2007.

BARUCH, Yehuda. Career systems in transition: A normative model for organizational career practices. Personnel Review, [S. 1.], v. 32, Issue 2, p. 231-251, 2003.

BRESSER PEREIRA, Luiz Carlos. Assalto ao Estado e ao mercado, neoliberalismo e teoria econômica. Estudos Avançados, São Paulo, v. 23, n. 66, 2009. Disponível em:

$<$ http://www.scielo.br/scielo.php?script=sci_arttext\&pid=S0103-40142009000200002 >. Acesso em: 16 maio 2010.

BRÍGIDO, Raimundo. Inteligência, desempenho, qualificação e certificação da competência. 2005. (Resumo). Disponível em:

$<$ http://cinterfor.org.uy/public/spanish/region/ampro/cinterfor/temas/complab/evento/sem_sen /cer_com.doc>. Acesso em: 12 mar. 2010.

CASTRO, José Henrique Motta de; KILIMNIK, Zélia Miranda; SANT’ANNA, Anderson de Souza. Modernidade organizacional em gestão de pessoas como base para a incorporação de modelo de gestão por competências. RAC - Eletrônica, Curitiba, v. 2, n. 1, p. 105-122, jan./abr. 2008.

CHARAUDEAU, Patrick. Langage et discours: élements de sémiolinguistique (théorie et pratique). Paris: Hachette, 1983.

CHARAUDEAU, Patrick. O discurso político. In: EMEDIATO, Wander; MACHADO, Ida Lúcia; MENEZES, William (Org.). Análise do discurso: gêneros, comunicação e sociedade. Belo Horizonte: NAD, POSLIN, FALE-UFMG, 2006.

CHARAUDEAU, Patrick. Linguagem e discurso: modos de organização. Tradução de Angela M. S. Correa e Ida Lúcia Machado. 2. ed. São Paulo: Contexto, 2010. 
Luiz Claudio Vieira de Oliveira, Zélia Miranda Kilimnik \& Rafael Parreira de Oliveira

CHEN, Hai Ming; CHANG, Wen Yen. Core competence: from a strategic human resource management perspective. African Journal of Business Management, [S. 1.], v. 5, n. 14, p. 5738-5745, July 2011. Disponível em:

$<$ http://www.academicjournals.org/AJBM/PDF/pdf2011/18\%20July/Chen\%20and\%20Chang. pdf>. Acesso em: 29 jun. 2011.

CLARK, James W. Career plateaus in retail management. In: ANNUAL MEETING OF THE ASSOCIATION OF COLLEGIATE MARKETING EDUCATORS, 2005. Proceedings... [S. 1.: s. n.], 2005. Disponível em: <http://sbaer.uca.edu/research/acme/2005/09.pdf>. Acesso em: 27 jun. 2012.

COUTINHO, Maria Chalfin; KRAWULSKI, Edite; SOARES, Dulce Helena Penna. Identidade e trabalho na contemporaneidade: repensando articulares possíveis. Psicologia \& Sociedade, Florianópolis, v. 19, p. 29-37, 2007. Edição Especial 1. Disponível em: <http://www6.ufrgs.br/seerpsicsoc/ojs/viewarticle.php?id=151>. Acesso em: 2 abr. 2010.

DEMO, Gisella et al. Políticas de gestão de pessoas no novo milênio: cenário dos estudos publicados nos periódicos da área de Administração entre 2000 e 2010. RAM - Revista de Administração Mackenzie, São Paulo, v. 12, n. 5, p. 15-42, set./out. 2011. Disponível em: $<$ http://www.scielo.br/scielo.php?pid=S1678-

$69712011000500002 \&$ script=sci_abstract\&tlng=pt>. Acesso em: 25 jun. 2012.

DOLABELLA, Rosemirtes; BITENCOURT, Claudia Cristina. A consolidação das competências organizacionais na vitivinicultura brasileira: um estudo de caso na Vinícola Miolo. In: ENCONTRO DA ASSOCIAÇÃO NACIONAL DE PÓS-GRADUÇÃO E PESQUISA EM ADMINISTRAÇÃO, 30., 2006, Salvador. Anais... Rio de Janeiro: ANPAD, 2006. 1 CD-ROM.

DOSSE, François. História do estruturalismo. Tradução de Álvaro Cabral. São Paulo: Ensaio; Campinas: Unicamp, 1993. v. 1: O campo do signo, 1945/1966.

DREJER, A. Strategic management and core competencies. London: Quorumbooks, 2002.

DUBERLEY, Joanne; COHEN, Laurie; LEESON, Elspeth. Constructing scientific careers: change, continuity and context. Organization Studies, London, v. 27, n. 8, p. 1131-1152, 2006 .

DUBERLEY, Joanne; COHEN, Laurie; LEESON, Elspeth. Exploring career transitions: accounting for structure and agency. Personnel Review, Bingley, v. 35, n. 3, p. 281-296, 2006b.

REAd I Porto Alegre - Edição 75 - N 2 - maio/agosto 2013 - p. 301-329 
Da gerência para a docência: metáforas do discurso de transição

DUBOIS, D. D.; ROTHWELL, W. J. Competency-based human resource management. California: Davies-Black Publishing, 2004.

DUTRA, Joel Souza; FISCHER, André Luiz; RUAS, Roberto de Lima; NAKATA, Lina Eiko. Absorção do conceito de competência em gestão de pessoas: a percepção dos profissionais e as orientações adotadas pelas empresas. In: ENCONTRO DA ASSOCIAÇÃO NACIONAL DE PÓS-GRADUÇÃO E PESQUISA EM ADMINISTRAÇÃO, 30., 2006, Salvador. Anais... Rio de Janeiro: ANPAD, 2006. 1 CD-ROM.

FLEURY, Afonso C. C.; FLEURY, Maria Tereza Leme. Estratégias competitivas e competências essenciais: perspectivas para a internacionalização da indústria no Brasil. Gestão \& Produção, São Carlos, v. 10, n. 2, Aug. 2003. ISSN 0104-530X. Disponível em: $<$ http://www.scielo.br/scielo.php?script=sci_arttext\&pid=S0104-30X2003000200002>. Acesso em: 15 maio 2010.

GRIPA, Francielly Sirtoli. ERP - Enterprise Resource Planning (Sistemas Integrados de Gestão. 2007. 62 f. TCC (Bacharelado em Sistemas de informação) - Curso de Sistemas de Informação da Faculdade de Ciências Aplicadas "Sagrado Coração", Linhares, 2007. Disponível em: <http://www.gfsolucoes.net/trabalhos/implantacao_erp.pdf>. Acesso em: 20 jun. 2012.

HALL, Stuart. Identidade cultural na pós-modernidade. Tradução de Tomaz Tadeu da Silva e Guacira Lopes Louro. 5. ed. Rio de Janeiro: DP\&A, 2001.

HANASHIRO, Darcy Mitiko Mori; NASSIF, Vânia Maria Jorge. Competências de professores: um fator competitivo. RBGN Revista Brasileira de Gestão de Negócios, São Paulo, v. 8, n. 20, p. 45-56, jan./abr. 2006. Disponível em:

<http://www.fecap.br/extensao/artigoteca/Art_009.pdf>. Acesso em: 21 maio 2010.

HERMAN, Jeffrey et al. Motivated by the organization's mission or their career? Implications for leaders in turbulent times. [S. 1.]: Center for creative Leadership and Booz Allen Hamilton, 2011. Disponível em:

$<$ http://www.ccl.org/leadership/pdf/research/MotivatedMissionCareer.pdf>.

Acesso em: 20 jun. 2012.

KILIMNIK, Zélia Miranda; CASTILHO, Isolda Veloso de; SANT'ANNA, Anderson de Souza. Carreiras em transformação e seus paradoxais reflexos nos indivíduos: metáforas de carreira e de competências. Comportamento organizacional e gestão, Lisboa, v.12, n. 2, p. 257-280, 2006.

KILIMNIK, Zélia Miranda; SANT'ANNA, Anderson de Souza; CASTILHO, Isolda Veloso de. Carreiras em transformação e seus paradoxais reflexos nos indivíduos: pesquisa de metáforas e âncoras de carreira, associada à representação de competências profissionais.

REAd I Porto Alegre - Edição 75 - N 2 - maio/agosto 2013 - p. 301-329 
Luiz Claudio Vieira de Oliveira, Zélia Miranda Kilimnik \& Rafael Parreira de Oliveira

Revista GES - Gestão e Sociedade, Belo Horizonte, v. 2, n. 3, p. 2-38, 2008. Disponível em: $<$ http://www.face.ufmg.br/revista/index.php/gestaoesociedade/issue/view/87>. Acesso em: 5 abr. 2010.

KILIMNIK, Zélia Miranda; SANT'ANNA, Anderson de Souza; OLIVEIRA, Luiz Claudio Vieira de; BARROS, Delba Teixeira Rodrigues. Seriam as âncoras de carreiras estáveis ou mutantes? Um estudo com profissionais de Administração em transição de carreira. Revista Brasileira de Orientação Profissional, São Paulo, v. 9, n. 1, p. 43-60, 2008.

LE BOTERF, G. Desenvolvendo a competência dos profissionais. Porto Alegre: Artmed, 2003.

LEAL, Raimundo S.; BANDEIRA, Anselmo Alves. Avaliação de desempenho enquanto elemento de potencialização da gestão do conhecimento. In: ENCONTRO DE ADMINISTRAÇÃO DA INFORMAÇÃO, 2., 2009, Recife. Anais... Recife: ENADI, 2006. 1 CD-ROM.

MACIEL, Maria José Camelo. O modelo das competências e o perfil profissional dos trabalhadores do terciário de fortaleza: entre as representações teóricas e a realidade. 2002. 165 f. Dissertação (Mestrado acadêmico em políticas públicas e sociedade) - Universidade Estadual do Ceará, Fortaleza, 2002.

MUNCK, Luciano; MUNCK, Maria Gomes Musetti; SOUZA, Rafael Murim de. Gestão de pessoas por competências: análise de repercussões dez anos pós-implantação. RAM Revista de Administração Mackenzie, São Paulo, v. 12, n. 1, p. 4-52, jan./fev. 2011. Disponível em: <http://www.scielo.br/pdf/ram/v12n1/a02v12n1.pdf>. Acesso em: 30 jun. 2012.

ONGORI, Henry; AGOLLA, Joseph. Paradigm shift in managing career plateau in organization: The best strategy to minimize employee intention to quit. African Journal of Business Management, [S. 1.], v. 3, n. 6, p. 268-271, June 2009. Disponível em: $<$ http://www.academicjournals.org/AJBM/PDF/pdf2009/Jun/Ongori\%20and\%20Agolla.pdf>. Acesso em: 28 jun. 2012.

PAIVA, Kely César Martins de; MELO, Marlene Catrina de Oliveira Lopes. Competências profissionais docentes e sua gestão em universidades mineiras. In: ENCONTRO DE GESTÃO DE PESSOAS E RELAÇÕES DE TRABALHO - EnGPR, 2., 2009, Curitiba. Anais... Curitiba: GPR, 2009. 1 CD-ROM.

PALMERO, Sandra; ROGER, Alain; TREMBLAY, Michel. Work satisfaction and career plateau of par-time workers. In: EGOS COLLOQUIUM LYON, 17., 2001, Lyon. Annales... Lyon: EGOS, 2001. Disponível em: <http://centremagellan.univlyon3.fr/fr/articles/88_567.pdf>. Acesso em: 28 jun. 2012. 
Da gerência para a docência: metáforas do discurso de transição

PERRENOUD, Philippe. Construir as competências desde a escola. Porto Alegre: Artes Médicas Sul, 1999.

PERRENOUD, Philippe. Práticas pedagógicas, profissão docente e formação: perspectivas sociológicas. Lisboa: Dom Quixote, 1993.

PORTER, Michael E. Competição: estratégias competitivas essenciais. Tradução de Afonso Celso da Cunha Serra. Rio de Janeiro: Campus, 1999.

REYES, José Antonio Aravena et al. A implementação do sistema de gestão de pessoas por competência. Estudo de caso: DaimlerChrysler do Brasil. In: ENCONTRO NACIONAL DE ENGENHARIA DE PRODUÇÃO, 25., 2005, Porto Alegre. Anais... Porto Alegre: ENEGEP, 2005. Disponível em:

<http://www.abepro.org.br/biblioteca/ENEGEP2005_Enegep0901_0830.pdf>. Acesso em: 28 jun. 2012.

RICHARDSON, R. et al. Pesquisa social: métodos e técnicas. São Paulo: Atlas, 1985 apud SANT'ANNA, Anderson de Souza; MORAES, Lúcio Flávio Renault de; KILIMNIK, Zélia Miranda. Competências individuais, modernidade organizacional e satisfação no trabalho: um estudo de impactos. In: SEMINÁRIOS EM ADMINISTRAÇÃO FEA-USP (SEMEAD), 6. 2003, São Paulo. Anais... São Paulo: SEMEAD, 2003.

RODRIGUES JÚNIOR, Francisco José Freire; CABRAL, Augusto Cézar de Aquino; SOARES, Robson Teixeira. Alinhando competências e estratégias organizacionais: um estudo no setor de telecomunicações. In: ENCONTRO DA ASSOCIAÇÃO NACIONAL DE PÓSGRADUÇÃO E PESQUISA EM ADMINISTRAÇÃO, 30., 2006, Salvador. Anais... Rio de Janeiro: ANPAD, 2006. 1 CD-ROM.

ROWE, Diva Ester Okazaki; BASTOS, Antonio Virgílio Bittencourt. Organização e/ou carreira? Comparando docentes de IESs públicas e privadas quanto à estrutura de seus vínculos de comprometimento no trabalho. In: ENCONTRO DA ASSOCIAÇÃO NACIONAL DE PÓS-GRADUAÇÃO E PESQUISA EM ADMINISTRAÇÃ̃O, 31., 2007, Rio de Janeiro. Anais... Rio de Janeiro: ANPAD, 2007. 1 CD-ROM.

SANT'ANNA, Anderson de Souza; REIS, Valéria Regina Amaral Torres; KILIMNIK, Zélia Miranda. Competências individuais e modernidade organizacional: um estudo com graduandos em Administração. Administração: Ensino e Pesquisa - RAEP, Rio de Janeiro, v. 7, n. 3, p. 23-40, jul./ago./set. 2006.

SANT'ANNA, Anderson de Souza. Profissionais mais competentes, políticas e práticas de gestão mais avançadas? RAE-eletrônica, São Paulo, v. 7, n. 1, jan./jun. 2008. Disponível em: <http://www16.fgv.br/rae/artigos/3908.pdf>. Acesso em: 25 nov. 2010.

REAd I Porto Alegre - Edição 75 - Nº 2 - maio/agosto 2013 - p. 301-329 
Luiz Claudio Vieira de Oliveira, Zélia Miranda Kilimnik \& Rafael Parreira de Oliveira

SANTOS, Ana Cristina Batista dos; NEPOMUCENO, Luciana Holanda. Os sistemas de informação como estruturantes da organização burocrática contemporânea: reflexões sobre as mudanças organizacionais e individuais relacionadas à inovação tecnológica em uma indústria brasileira. In: ENCONTRO DE ADMINISTRAÇÃO DA INFORMAÇÃO, 2., 2009, Recife. Anais... Recife: ENADI, 2006.

SAUSSURE, Ferdinand de. Curso de linguística geral. Tradução de Antônio Chelini et al. 9. ed. São Paulo: Cultrix, 1970.

SCHEIN, E. Career anchors: discovering your real values. San Diego, CA: Pfeiffer \& Company, 1993.

SILVA, Edna Lúcia; CUNHA, Miriam Vieira da. A formação profissional no século XXI: desafios e dilemas. Ci. Inf. - Ciência da Informação, Brasília, v. 31, n. 3, p. 77-82, set./dez. 2002. Disponível em: <http://www.scielo.br/pdf/\%0D/ci/v31n3/a08v31n3.pdf>. Acesso em: 15 mar. 2010.

SMITH, R. Harnessing competencies, capabilities and resources. Technology Management, Arlington, v. 51, n. 5, p. 47-53, Sept./Oct. 2008.

ZARIFIAN, P. Compétences et organization qualificante en milieu industriel. In: MINET, Francis; PARLIER, Michel; WITTE, Serge. La competence: mythe, construction ou realité? Paris: Liaisons, 1994.

ZARIFIAN, P. Objetivo Competência. São Paulo: Atlas, 2001. 